\title{
Simvastatin and purine analogs have a synergic effect on apoptosis of chronic lymphocytic leukemia cells
}

\author{
Monika Podhorecka • Dorota Halicka • Piotr Klimek • \\ Malgorzata Kowal • Sylwia Chocholska • \\ Anna Dmoszynska
}

Received: 1 April 2010 / Accepted: 5 May 2010/Published online: 25 May 2010

(C) The Author(s) 2010. This article is published with open access at Springerlink.com

\begin{abstract}
Despite many therapeutic regimens introduced recently, chronic lymphocytic leukemia (CLL) is still an incurable disorder. Thus, there is an urgent need to discover novel, less toxic and more effective drugs for CLL patients. In this study, we attempted to assess simvastatin, widely used as a cholesterol-lowering drug, both as a single agent and in combination with purine analogs - fludarabine and cladribine - in terms of its effect on apoptosis and DNA damage of CLL cells. The experiments were done in ex vivo short-term cell cultures of blood and bone marrow cells from newly diagnosed untreated patients. We analyzed expression of active caspase- 3 and the BCL-2/BAX ratio as markers of apoptosis and the expression of phosphorylated histone $\mathrm{H} 2 \mathrm{AX}$ (named $\gamma \mathrm{H} 2 \mathrm{AX}$ ) and activated ATM kinase (ataxia telangiectasia mutated kinase), reporters of DNA damage. Results of our study revealed that simvastatin induced apoptosis of CLL cells concurrently with lowering of BCL-2/ $\mathrm{BAX}$ ratio, and its pro-apoptotic effect is tumor-specific, not affecting normal lymphocytes. We observed that combinations of simvastatin+fludarabine and simvastatin+cladribine had a synergic effect in inducing apoptosis. Interestingly, the rate of apoptosis caused by simvastatin alone and in combination was independent of markers of disease progression like ZAP-70 and CD38 expression or clinical stage according to Rai classification. We have also seen an increase in $\gamma \mathrm{H} 2 \mathrm{AX}$
\end{abstract}

M. Podhorecka $(\bowtie) \cdot$ P. Klimek $\cdot$ M. Kowal $\cdot$ S. Chocholska

A. Dmoszynska

Department of Haematooncology and Bone Marrow

Transplantation, Medical University of Lublin,

Staszica 11,

20-081 Lublin, Poland

e-mail: monika.podhorecka@am.lublin.pl

D. Halicka

Brander Cancer Research Institute, New York Medical College,

Valhalla, NY, USA expression in parallel with activation of ATM in most of the analyzed samples. The results suggest that simvastatin can be used in the treatment of CLL patients as a single agent as well as in combination with purine analogs, being equally effective both in high-risk and good-prognosis patients. One of the mechanisms of simvastatin action is inducing DNA damage that ultimately leads to apoptosis.

Keywords Apoptosis · CLL · DNA damage ·

Purine analogs $\cdot$ Simvastatin

\section{Introduction}

Chronic lymphocytic leukemia (CLL), the most common type of adult leukemia in Western countries characterized by the accumulation of malignant CD19+/ CD5+ cells, is a heterogeneous disease with highly variable clinical course and prognosis $[1,2]$. Some patients have indolent disease and never need treatment, but in others the clinical course is aggressive and soon after diagnosis requires intensive treatment [3, 4]. Symptomatic CLL can be effectively treated with purine analogs, glucocorticoids, alkylating agents, or monoclonal antibodies; however, some patients with relapsed or refractory disease have limited therapeutic options. Thus, there is an urgent need to discover less toxic and more effective drugs for CLL patients. In an attempt to find new modalities, the use of immunomodulatory drugs or plant-derived substances was reported to improve results in CLL treatment.

Statins are inhibitors of 3-hydroxy-3-methylglutaryl coenzyme A reductase, the enzyme responsible for synthesis of mevalonate, a precursor of cholesterol. Statins were developed as cholesterol-lowering drugs and are widely used for the prevention and treatment of cardiovascular diseases or brain stroke [5, 6]. They are generally regarded as safe drugs, 
although liver transaminase elevations and myopathy have been reported [7, 8]. Recently, it has been indicated that statins have cytostatic properties against several types of cancer cell lines, and in several in vitro models, statins sensitize human tumor cells to cytostatic drugs [9]. It has also been suggested that they may be used as chemopreventive agents based on reports indicating a decreased risk of cancer in patients with cardiovascular disease treated with statins [9-11]. Statins have been shown to either cause growth arrest or induce apoptosis in several tumor-derived cells in vitro, and they display synergism with chemotherapeutic agents [12-15]. It was also demonstrated that exposure of clonal B lymphocytes from CLL patients to simvastatin decreases their viability by induction of apoptosis [16].

In this study, we examined the ex vivo effects of simvastatin alone and in combination with purine analogs fludarabine and cladribine in terms of its effect on apoptosis of CLL leukemic cells and normal lymphocytes derived from peripheral blood and bone marrow. We have also assessed the DNA damage response in cells treated with simvastatin. We estimated the percentage of cells expressing active caspase-3, a marker of apoptosis, and intracellular expression of BCL-2 and BAX proteins, regulators of the apoptotic process. The DNA damage response was assessed by measuring expression of phosphorylated histone $\mathrm{H} 2 \mathrm{AX}$ (named $\gamma \mathrm{H} 2 \mathrm{AX}$ ) and activation of ATM kinase (ataxia telangiectasia mutated kinase). Subsequently, these apoptosis and DNA damage markers were correlated with ZAP-70 and CD38 expression, lymphocyte counts, lactate dehydrogenase (LDH) and $\beta 2$-microglobulin levels, and clinical stadium according to Rai classification.

\section{Materials and methods}

\section{Patients}

Fifteen newly diagnosed, untreated CLL patients were enrolled in the study. Diagnosis of CLL was made on the basis of clinical examination and morphological and immunological criteria. Peripheral blood and bone marrow samples were obtained from the patients after informed consent. The study was approved by the Local Ethical Committee.

\section{Cell isolation and culture}

Peripheral blood and bone marrow mononuclear cells were isolated by density gradient centrifugation using Biocoll Separating Solution (Biochrom AG, Germany). Then the cells were resuspended in culture medium consisting of RPMI 1640 with $2 \mathrm{mM}$ L-glutamine, 100 units/ml penicillin, $100 \mu \mathrm{g} / \mathrm{ml}$ streptomycin, and $10 \%$ fetal calf serum at a final density of $2 \times 10^{6}$ cells $/ \mathrm{ml}$. This culture medium was supplemented with simvastatin at a concentration of
$10 \mu \mathrm{M}$, fludarabine at a concentration of $1 \mu \mathrm{g} / \mathrm{ml}$, cladribine at a concentration of $1.4 \mu \mathrm{g} / \mathrm{ml}$, or the mixture of simvastatin and fludarabine or simvastatin and cladribine, respectively. Prior to use, simvastatin was activated by dissolving it in $100 \mu \mathrm{l}$ of ethanol according to an activation procedure proposed by Sadeghi et al. [17]. Reagents that we used were obtained from Sigma-Aldrich Chemie $\mathrm{GmbH}$, Germany.

The cells were exposed to the drugs for 0,2 and $24 \mathrm{~h}$ in culture; the cells treated for $2 \mathrm{~h}$ were analyzed for H2AX phosphorylation and ATM activation, while those treated for $24 \mathrm{~h}$ were assessed for frequency of apoptosis. In the first three experiments, we used two control cultures, one in ethanol at $0.01 \%$ concentration and the other without ethanol. Since the differences in the percentage of apoptotic cells between these two cultures were no higher than $0.6 \%$, in the next experiments the respective cell samples were incubated in the absence of any drug for periods of time equivalent to the drug-treated cells.

Immunocytochemical detection of activated caspase-3 and $\mathrm{BCL}-2$ and $\mathrm{BAX}$ proteins

The samples of blood and bone marrow untreated or treated in cultures with simvastatin, fludarabine, cladribine, or a mixture of these drugs $\left(\sim 10^{5}\right.$ cells) were initially incubated for $15 \mathrm{~min}$ with anti-CD19 peridinin chlorophyll (PerCP)-conjugated and anti-CD5 allophycocyanin (APC)-conjugated monoclonal antibody (mAb) (DAKO, Denmark) at room temperature. Subsequently, the cells were subjected to fixation and permeabilization procedures using an IntraPrep kit (Immunotech, France) following the manufacturer's instruction. The cells were then incubated with the anti-active caspase-3 $\mathrm{mAb}$, phycoerythrin (PE)-conjugated (Pharmingen, USA); anti-intracellular BAX $\mathrm{mAb}$, flourescein isothiocyanate (FITC)-conjugated (Santa Cruz Biotechnology, USA); antiintracellular BCL-2 mAb, PE-conjugated (Pharmingen, USA); or an isotype-matched negative control (Dako, Denmark) in darkness at room temperature for $15 \mathrm{~min}$.

Immunocytochemical detection of $\gamma \mathrm{H} 2 \mathrm{AX}$ and ATM activation

The samples of blood untreated or treated in cultures with simvastatin, fludarabine, cladribine, or a mixture of these drugs $\left(\sim 10^{5}\right.$ cells $)$ were initially incubated for $15 \mathrm{~min}$ with anti-CD19 PerCP and anti-CD5 APC-conjugated mAb (DAKO, Denmark) at room temperature. Subsequently, the cells were subjected to fixation and permeabilization using an IntraPrep kit (Immunotech, France) following the manufacturer's instruction. The cells were then incubated with Ser139-phosphorylated H2AX mAb conjugated with FITC (BioLegend, USA) or anti-phospho ATM (Ser-1981) $\mathrm{Ab}$ (Millipore, USA) labeled by the ZenonTM Alexa Fluor ${ }^{\circledR}$ 488 Mouse IgG1 Labeling Kit (Molecular Probes, USA). 


\section{Fluorescence measurement}

The samples were measured by a FACSCalibur (Becton Dickinson). For each sample, 10,000 cells were measured. The CD5+/CD19+ population was initially gated, and further analysis of leukemic cells was carried out for this population. To determine the frequency of apoptosis, the percentage of active caspase- 3 cells relative to that in the control cells was calculated. The mean BCL-2 and BAX immunofluorescence intensity (IF) was estimated for each sample. The BCL2/BAX IF ratio for CD19+/CD5+ cells was then calculated. The analysis of non-leukemic cells was carried out for CD19+/CD5- and CD19-/CD5+ populations, which represented normal $\mathrm{B}$ and $\mathrm{T}$ cells, respectively. The percentage of cells with expression of active caspase- 3 was estimated for these populations. We have performed such an analysis in seven out of 15 patients in which the percentage of non-leukemic cells in both peripheral blood and bone marrow was higher than $10 \%$.

The mean $\gamma \mathrm{H} 2 \mathrm{AX}$ and activated ATM IF intensity was estimated per sample. The data reporting drug effects on CLL cells are shown as the drug-induced increase in mean $\gamma \mathrm{H} 2 \mathrm{AX}$ IF or $\mathrm{ATM}^{\mathrm{P} 1981}$ IF over the respective values of the control cells, which were run in parallel with the drug-treated ones.

Flow cytometric analysis of ZAP-70 and CD38 expression

A total of $1 \times 10^{6}$ peripheral blood cells were stained with mAbs CD19 PE (BD Pharmingen), CD5 CyChrome (Caltag Laboratories, USA) or CD3 PE (BD Pharmingen). Following membrane staining, the cells were fixed and permeabilized with $70 \%$ ethanol for $1 \mathrm{~h}$ at $-20^{\circ} \mathrm{C}$. After washing, the anti-ZAP-70 antibody (Biomol Research Laboratories, USA) labeled by the ZenonTM Alexa Fluor ${ }^{\circledR}$ 488 Mouse IgG2a Labeling Kit (Molecular Probes, USA) was added to the sample tubes. The samples were incubated for $30 \mathrm{~min}$, washed, and analyzed by flow cytometry. Patients were considered positive for ZAP-70 when the expression was found in $20 \%$ or more of leukemic cells.

To assess CD38 expression, peripheral blood mononuclear cells were stained with anti-CD38 FITC (BD Pharmingen), anti-CD19 PE, anti-CD5 CyChrome MoAbs, or IgG1 isotypic control for $20 \mathrm{~min}$ in darkness and analyzed by flow cytometry. Patients were considered CD38 positive when the expression was found in at least $20 \%$ of leukemic cells.

Evaluation of cooperative index

To evaluate the synergism between simvastatin and fludarabine or cladribine, a cooperative index (CI) based on the Chou-Talalay method was calculated [18-20]. The following formula was used: $\mathrm{CI}=$ (sum of specific apoptosis of single- agent treatment/specific apoptosis of combined treatment). The percentage of specific apoptosis was determined using the following formula: specific apoptosis $=$ (drug induced apoptosis - spontaneous apoptosis $) /(100-$ spontaneous apoptosis) $\times 100 \%$. When $\mathrm{CI}<1, \mathrm{CI}=1$, and $\mathrm{CI}>1$, the effects were defined as synergistic, additive, and infraadditive, respectively [21, 22].

Fluorescence in situ hybridization

In the analysis of chromosome alterations characteristic of CLL, locus-specific probes for 11q22.3 (LSI ATM), 17 p13.1 (LSI TP53), 13q.14.3 (D13S319), and the chromosome 12 centromere (CEP12) (Abbott Diagnostics) were used. Fluorescence in situ hybridization was performed according to the manufacturer's instructions. Probes were denatured at $73^{\circ} \mathrm{C}$ for $5 \mathrm{~min}$ and then applied to the determined areas on the slides. Following overnight hybridization at $37^{\circ} \mathrm{C}$, the slides were washed and air-dried in the darkness. Then, the slides were stained with DAPI and stored at $-20^{\circ} \mathrm{C}$ in the darkness. The samples were analyzed using the BX51 fluorescence microscope (OLYMPUS), and images were captured with a charge-coupled device camera using the CytoVision image analyzing system. At least 200 nuclei were analyzed for each probe. The cutoff value was $20 \%$ for each probe.

\section{Statistical analysis}

The statistical analysis was performed using STATISTICA 8.0 software for Windows. We used a Mann-Whitney $U$ test and a Spearman's $R$ test for two-independent-group analyses and two-variable-correlations, respectively. The Wilcoxon test was used for two-dependent-variables analyses. The $p<0.05$ standard was considered to be statistically significant.

\section{Results}

Simvastatin induces apoptosis of CLL leukemic cells derived from peripheral blood and bone marrow

Figure 1 presents the data reporting the induction of apoptosis in peripheral blood and bone marrow CLL cells treated ex vivo with simvastatin. The percentage of cells with caspase- 3 expression in 24-h cultures with simvastatin was significantly higher than the level of spontaneous apoptosis seen in the untreated 24-h parallel control cultures. Such an increase in the frequency of simvastatin-induced apoptosis was observed in the case of blood and bone marrow cultures with the percentage of apoptotic cells being significantly higher in bone marrow than in peripheral blood (Fig. 1a). We also 


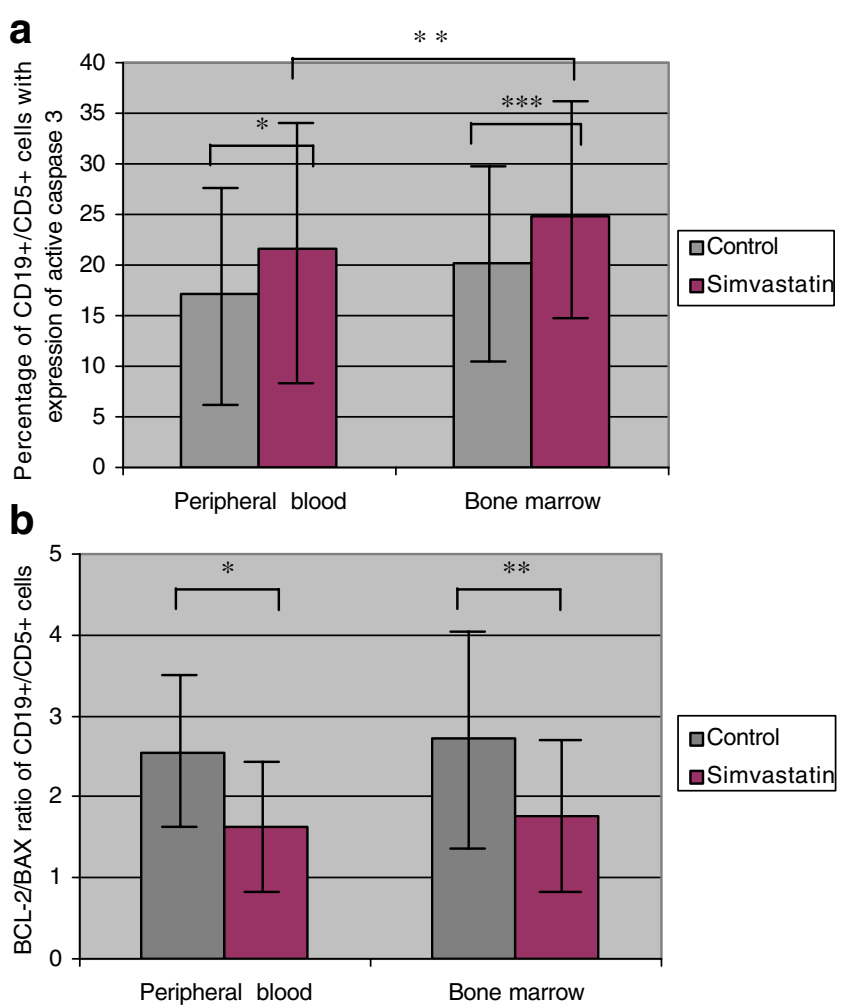

Fig. 1 Percentage of CD19+/CD5+ cells with active caspase-3 expression in cultures with simvastatin $(10 \mu \mathrm{M})$ in comparison to the control culture. The experiments were performed in a group of 15 patients. The statistically significant differences are shown in the figure: ${ }^{*} p=0.0006, * * p=0.001, * * * p=0.0009$ (a). BCL-2/BAX ratio of CD19+/CD5+ cells in cultures with simvastatin $(10 \mu \mathrm{M})$ after $24 \mathrm{~h}$ in comparison to the control $0 \mathrm{~h}$ culture. A decrease in the ratio in the simvastatin-induced culture is observed after $24 \mathrm{~h}$. Experiments were performed in a group of 15 patients. The statistically significant differences are shown in the figure: ${ }^{*} p=0.001,{ }^{*} p=0.0009$ (b). Graphs represent means \pm standard deviations

detected a significant decrease in BCL-2/BAX ratio of CD19+/CD5+ in simvastatin-induced cultures after $24 \mathrm{~h}$ in comparison to the 0-h control culture (Fig. 1b).

Simvastatin synergizes with purine analogs to induce apoptosis of CLL cells

To assess the rate of apoptosis induced by simvastatin in combination with purine analogs, we measured the expression of active caspase-3 in CD19+/CD5+ peripheral blood cells in cultures with simvastatin+fludarabine and simvastatin+cladribine. Figure 2 illustrates the drug-induced increase in frequency of apoptotic cells above the level of spontaneous apoptosis seen in the untreated 24-h parallel control cultures. As is evident in Fig. 2a, the frequency of apoptosis in simvastatin+fludarabine-treated cultures was significantly higher than in simvastatin-treated cultures, and the same was true when compared with fludarabine-treated cultures. Such a significant increase in the rate of apoptosis was also observed in simvastatin+cladribine-treated cultures in comparison to both simvastatin cultures and cladribine cultures (Fig. 2b). Subsequently, to evaluate the effect of the combined action of simvastatin and purine analogs, the CI for each sample was calculated. The CI for simvastatin+fludarabine was $<1$ for 12 out of 15 analyzed patients, indicating the synergic effect in these samples. In one case, $\mathrm{CI}=1$, and in two cases, $\mathrm{CI}$ was $>1$, indicating the additive and the infra-additive effect, respectively. CI for simvastatin+cladribine was $<1$ in all except one of analyzed cases, indicating the synergic effect of these two drugs. The values of CI for each sample are presented in Fig. 2.

Simvastatin induces apoptosis of leukemic cells in a tumor-specific manner

To assess the effect of simvastatin as a single agent and in combination with purine analogs on non-leukemic cells, we measured the percentage of apoptotic cells with the expression of active caspase-3 in a population of CD19+/ CD5- and CD19-/CD5+ cells, which represented B and T cells, respectively. The results are shown in Fig. 3. We performed such an analysis in seven out of 15 patients in whom the percentage of non-leukemic cells in both peripheral blood and bone marrow was higher than $10 \%$. As is evident in Fig. 3, there was no apoptotic effect in the population of non-leukemic lymphocytes in culture with simvastatin, nor was the effect detected in samples of peripheral blood or bone marrow. Both fludarabine and cladribine caused apoptosis of normal cells; however, there was no statistically significant increase in the normal lymphocyte apoptosis rate in cultures with purine analogs combined with simvastatin in comparison to cultures with purine analogs only. Interestingly, the percentage of apoptotic cells from normal cell populations in cultures with purine analogs in patients No. 4,6, and 7, in whom cytogenetic abnormalities (del 17p or del 11q) were detected, was higher than the rate of purine analoginduced apoptosis of leukemic cells (to compare, see Figs. 2 and 3 and Table 1).

Rate of simvastatin-induced apoptosis of CLL cells is independent of ZAP-70 expression, CD38 expression, and clinical stadium according to Rai classification

To assess whether the rate of apoptosis caused by simvastatin is connected with the prognosis of CLL, the analyzed apoptotic parameters were compared in ZAP-70+ versus ZAP-70- cases as well as in CD38+ versus CD38- groups. We did not find statistically significant differences in the percentage of apoptotic caspase-3-positive cells in cultures with simvastatin between the ZAP-70- and ZAP-70+ groups. 

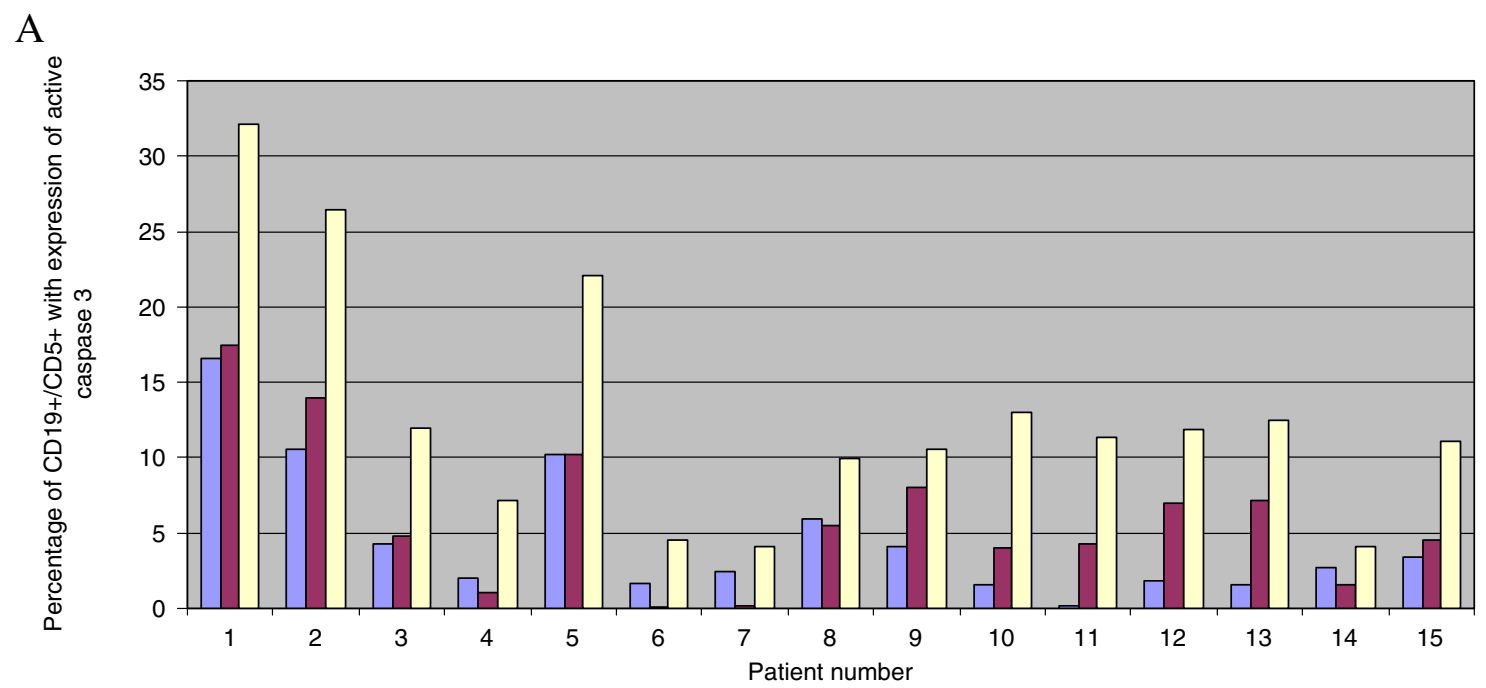

$\square$ Simvastatin $\square$ Fludarabine $\square$ Simvastatin+Fludarabine

\begin{tabular}{|c|c|c|c|c|c|c|c|c|c|c|c|c|c|c|c|}
\hline $\begin{array}{l}\text { Patient } \\
\text { number }\end{array}$ & 1 & 2 & 3 & 4 & 5 & 6 & 7 & 8 & 9 & 10 & 11 & 12 & 13 & 14 & 15 \\
\hline CI & 1.06 & 0.9 & 0.7 & 0.9 & 0.4 & 0.3 & 0.6 & 1.1 & 1 & 0.4 & 0.4 & 0.7 & 0.7 & 0.8 & 0.7 \\
\hline
\end{tabular}

$\mathrm{B}$

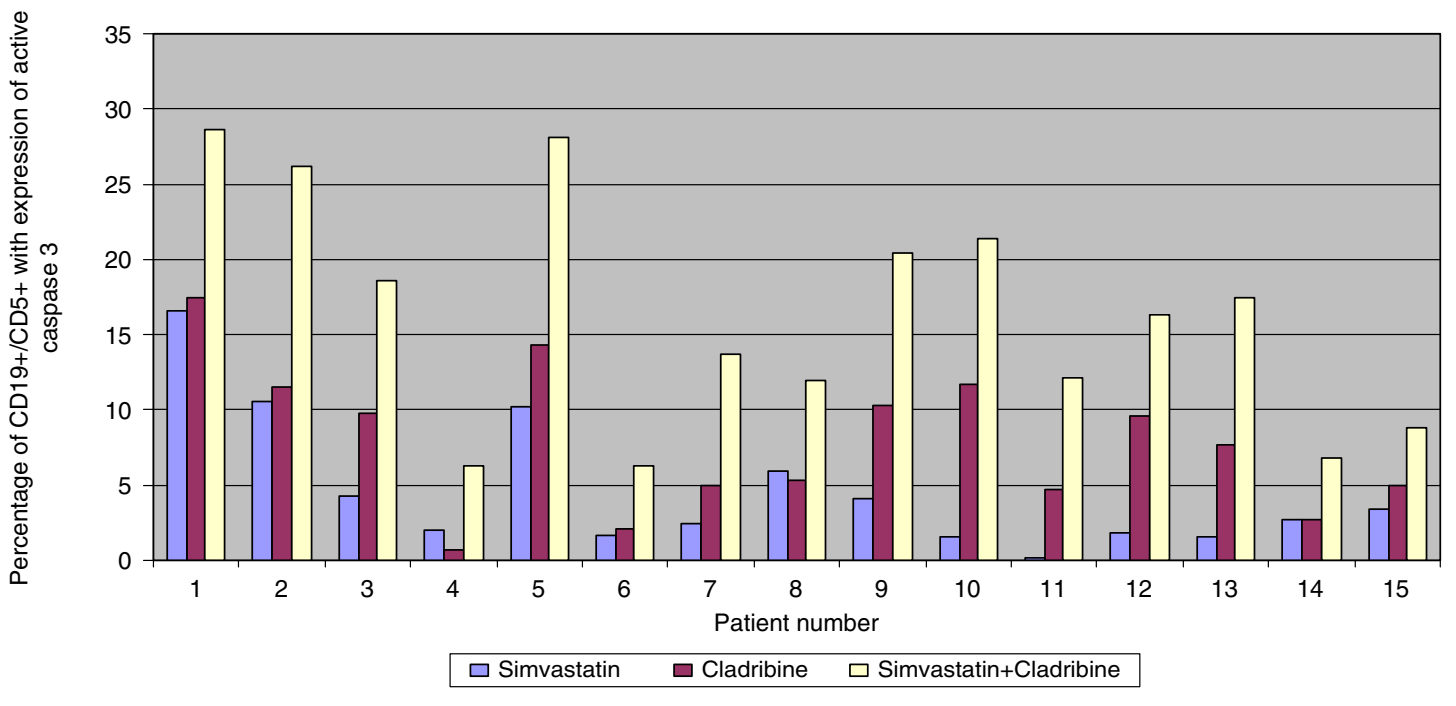

\begin{tabular}{cccccccccccccccc}
\hline $\begin{array}{c}\text { Patient } \\
\text { number }\end{array}$ & 1 & 2 & 3 & 4 & 5 & 6 & 7 & 8 & 9 & 10 & 11 & 12 & 13 & 14 & 15 \\
\hline CI & 1.1 & 0.8 & 0.7 & 0.8 & 0.4 & 0.5 & 0.5 & 0.9 & 0.6 & 0.6 & 0.4 & 0.7 & 0.5 & 0.7 & 0.9 \\
\hline
\end{tabular}

Fig. 2 Percentage of CD19+/CD5+ cells with expression of active caspase-3 in ex vivo 24 -h cultures with simvastatin $(10 \mu \mathrm{M})$, fludarabine $(1 \mu \mathrm{g} / \mathrm{ml})$, and simvastatin combined with fludarabine and the CI calculated for each sample (a). Percentage of CD19+/CD5+ cells with expression of active caspase-3 in ex vivo 24-h cultures with simvastatin $(10 \mu \mathrm{M})$, cladribine $(1.4 \mu \mathrm{g} / \mathrm{ml})$, and simvastatin combined with cladribine and the CI calculated for each sample (b). The data represent the drug-induced increase in the percentage of apoptotic cells above the respective values observed in the parallel control cultures. $\mathrm{CI}=$ (sum of specific apoptosis of single-agent treatment/specific apoptosis of combined treatment). The percentage of specific apoptosis was determined using the following formula: specific apoptosis $=($ drug induced apoptosis - spontaneous apoptosis $) /(100$ - spontaneous apoptosis) $\times 100 \%$. When $\mathrm{CI}<1, \mathrm{CI}=1$, and $\mathrm{CI}>1$, the effects were defined as synergistic, additive, and infra-additive, respectively 


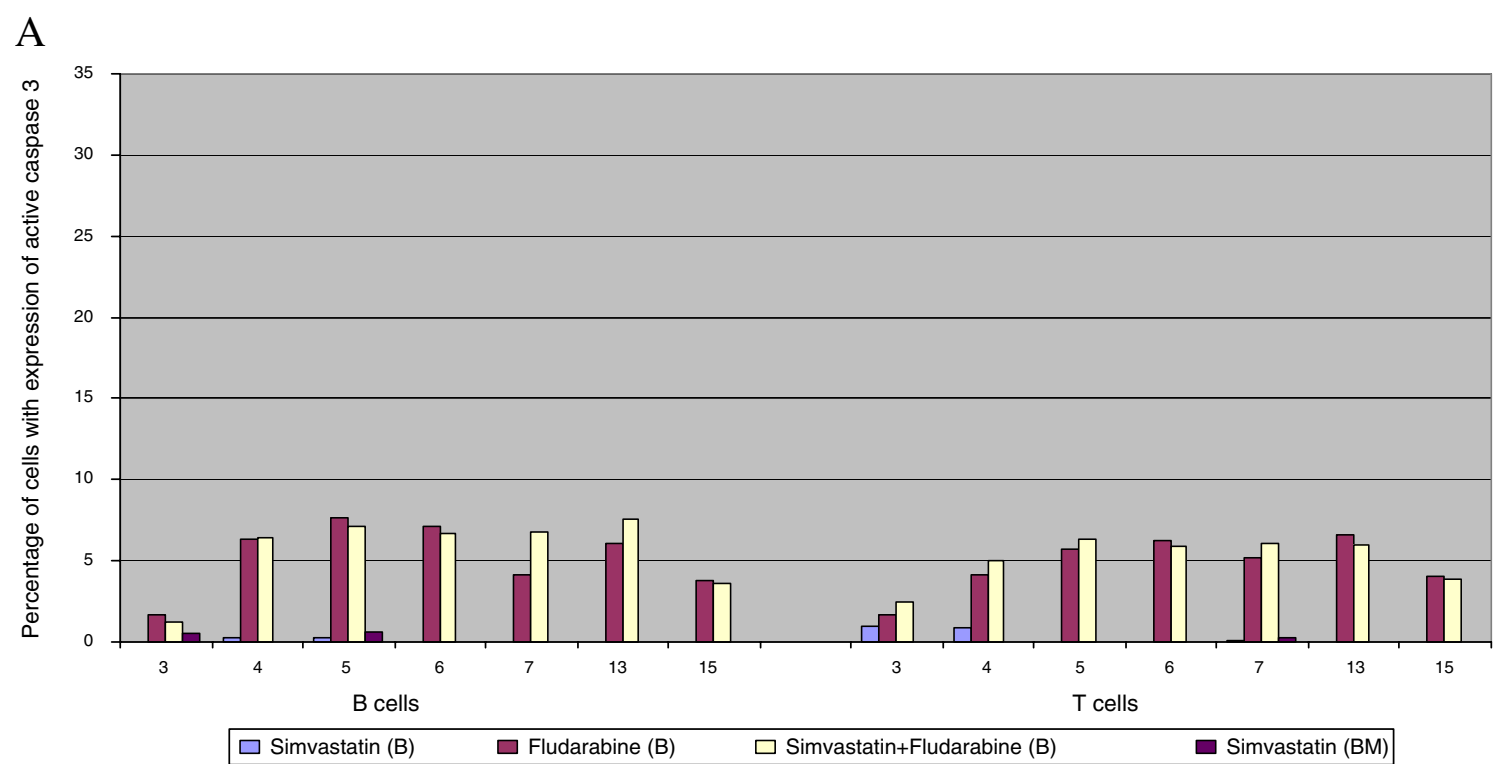

B

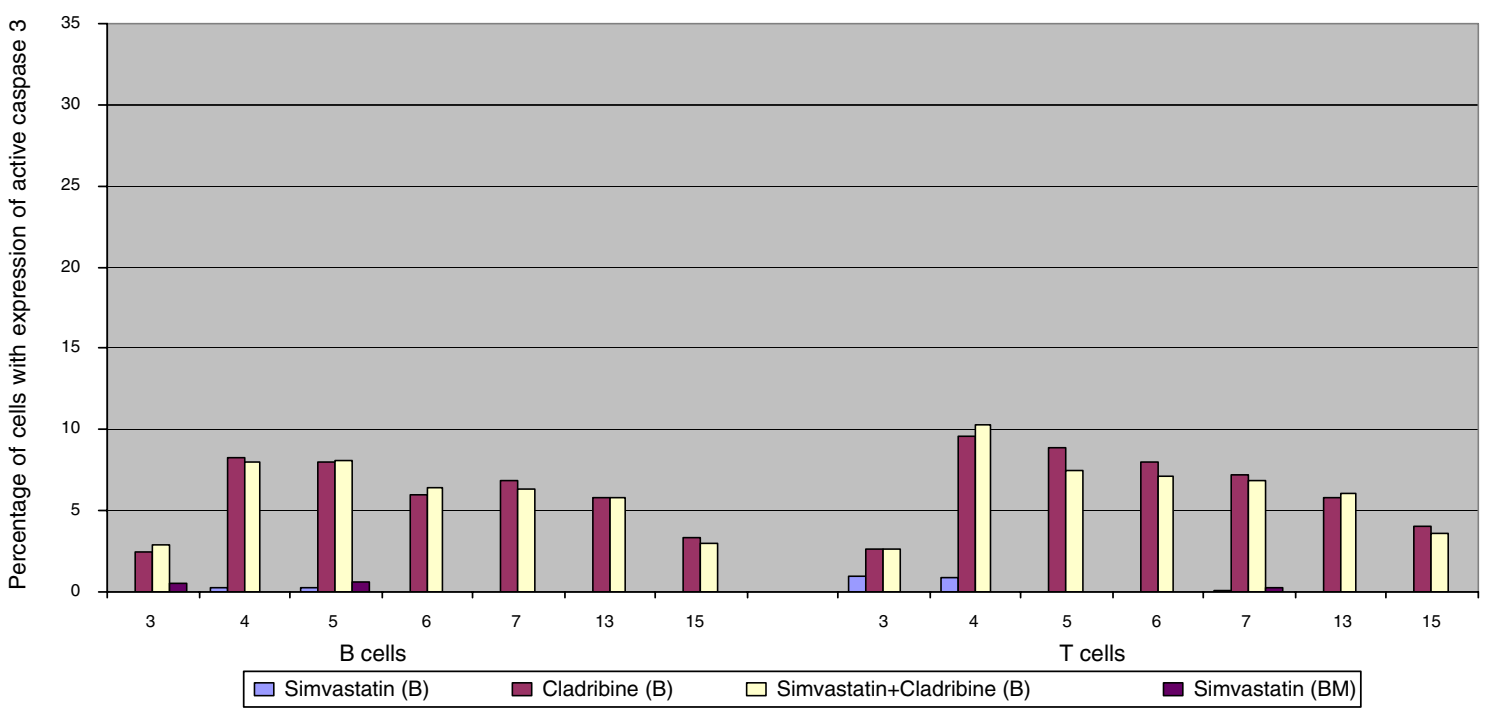

Fig. 3 Percentage of apoptotic cells with expression of active caspase-3 in populations of normal B (CD19+/CD5-) and T (CD19-/CD5+) cells in ex vivo 24-h cultures from the chosen patients. The analysis was performed in peripheral blood cultures with simvastatin, fludarabine, and simvastatin+fludarabine and bone marrow cultures with simvastatin. The concentrations of simvastatin and fludarabine were $10 \mu \mathrm{M}$ and $1 \mu \mathrm{g} / \mathrm{ml}$, respectively (a). Percentage of apoptotic cells with active caspase-3 expression in a population of normal B (CD19+/CD5-) and T (CD19-/ $\mathrm{CD} 5+$ ) cells in ex vivo 24-h cultures from the chosen patients. The analysis was performed in peripheral blood cultures with simvastatin,

Similarly, there were no statistically significant differences in the rates of apoptosis caused by simvastatin between CD38+ and CD38- patients.

We also assessed the rate of apoptosis caused by simvastatin as a single agent or in combination with purine analogs in groups of early $(0-1)$ versus advanced cladribine, and simvastatin+cladribine and bone marrow cultures with simvastatin. The concentrations of simvastatin and cladribine were $10 \mu \mathrm{M}$ and $1.4 \mu \mathrm{g} / \mathrm{ml}$, respectively (b). The data represent the druginduced increase in the percentage of apoptotic cells above the respective values observed in the parallel control cultures. The lack of bars observed in some cases means that there was no increase in the percentage of apoptotic cells above the level of these cells in controls. The scale in the figure is similar to that in Fig. 2 to make the comparison of changes between leukemic and normal cells easier. The numbers on the $X$-axis represent numbers of patients presented in Fig. 2

(2-4) stages of CLL according to the clinical Rai classification. No significant differences between these groups were found. The rate of simvastatin-induced apoptosis did not significantly correlate with such prognostic parameters like lymphocytosis, the lactate LDH level, or the $\beta-2$ microglobulin level. 
Table 1 Genetic abnormalities in CLL patients belonging to the group with no observable increase in $\gamma \mathrm{H} 2 \mathrm{AX}$ and activated ATM expression above the level of control expression in 24-h cultures with simvastatin (10 $\mu \mathrm{M}$ concentration)

\begin{tabular}{ll}
\hline Patient number & Genetic abnormalities \\
\hline 4 & $11 \mathrm{q} 22.3$ \\
5 & $13 \mathrm{q} 14.3$ \\
6 & $17 \mathrm{p} 13.1$, trisomy 12 \\
7 & $11 \mathrm{q} 22.1$ \\
8 & $11 \mathrm{q} 22.3$ \\
13 & No changes detected
\end{tabular}

In patient No. 5, a slight increase in activated ATM expression without an increase in $\gamma \mathrm{H} 2 \mathrm{AX}$ expression was observed, which is shown in Fig. 4

Simvastatin induces phosphorylation of $\mathrm{H} 2 \mathrm{AX}$ and activation of ATM in CLL cells

To explore whether treatment with simvastatin induces DNA damage, we measured the expression of phosphorylated H2AX and activated ATM, the markers of the DNA damage response, in CD19+/CD5+ cells. In most instances, an increase in $\gamma \mathrm{H} 2 \mathrm{AX}$ expression concurrent with the increase in expression of activated ATM was seen after $2 \mathrm{~h}$ of incubation with simvastatin, above the level of expression of these phosphoproteins in control cultures. The data showing the increase in $\gamma \mathrm{H} 2 \mathrm{AX}$ and activated ATM expression above the level of their expression in control culture in cells of individual patients are presented in Fig. 4. It is evident in Fig. 4, however, that the cells of a few patients were not affected at all. We also compared the rate of apoptosis caused by simvastatin in the group of patients where the increase in $\gamma \mathrm{H} 2 \mathrm{AX}$ expression above its "constitutive" level was observed (" $\gamma \mathrm{H} 2 \mathrm{AX}$ positive") and in the group where there was no increase in $\gamma \mathrm{H} 2 \mathrm{AX}$ expression (" $\gamma \mathrm{H} 2 \mathrm{AX}$ negative"). The rate of apoptosis was higher in " $\gamma \mathrm{H} 2 \mathrm{AX}$ positive" group than in " $\gamma \mathrm{H} 2 \mathrm{AX}$ negative one (Fig. 5).

When the data for all patients were compiled for statistical analysis, they revealed a significant increase in $\gamma \mathrm{H} 2 \mathrm{AX}$ IF caused by simvastatin in comparison with control cultures $(50.0 \pm 14.6$ and $53.1 \pm 14.4$, respectively, with $p=0.02)$. However, no significant differences were apparent between activated ATM expression in simvastatin-treated cultures and ATM expression in control cultures (181.2 \pm 59.2 and $184.9 \pm$ 64.4, respectively, $p>0.05$ ). The expression of $\gamma \mathrm{H} 2 \mathrm{AX}$ and activated ATM was not significantly dependent on ZAP-70 expression, CD38 expression, and clinical stadium according to Rai classification. However, the analysis of chromosome alterations in the " $\gamma \mathrm{H} 2 \mathrm{AX}$-negative" group revealed several genetic abnormalities that can be connected with no response to DNA damage caused by simvastatin. The data are presented in Table 1.

\section{Discussion}

Despite the many therapeutic regimens introduced recently, CLL is still an incurable disorder. Thus, there is an urgent need to discover novel, less toxic, and more effective drugs for CLL patients. Among several options, simvastatin was reported to induce apoptosis of leukemic cells in vitro and seems to be of interest in CLL patients [16]. It is known that statins induce apoptosis in a tumor-specific manner as shown in the case of tumor cells derived from acute myelogenous leukemia [14, 21, 22], multiple myeloma [23-25], and various cell lines [26]. It was also reported in several in vitro models that statins sensitize human tumor cells to cytostatic drugs [9].

Such properties of simvastatin inspired us to assess its effects on leukemic cells of CLL patients. Our results are consistent with the observations of Chapman-Shimshoni et
Fig. 4 Ex vivo induction of $\gamma \mathrm{H} 2 \mathrm{AX}$ and phosphorylated ATM $\left(\mathrm{ATM}^{\mathrm{P} 1981)}\right)$ in $\mathrm{CD} 5+/ \mathrm{CD} 19+$ cells treated with simvastatin $(10 \mu \mathrm{M})$ in 2 -h cultures. The data represent the drug-induced increase in expression of $\gamma \mathrm{H} 2 \mathrm{AX}$ $(\gamma \mathrm{H} 2 \mathrm{AX} \mathrm{IF})$ and activated ATM $\left(\mathrm{ATM}^{\mathrm{P} 1981} \mathrm{IF}\right)$ above the respective values observed in the parallel control cultures. No increase in expression of $\gamma \mathrm{H} 2 \mathrm{AX}$ after simvastatin treatment was detected in leukemic cells of patients No. 4, $5,6,7,8$, and 13 . In patient No. 5 , a slight increase in $\mathrm{ATM}^{\mathrm{P} 1981}$ expression was observed

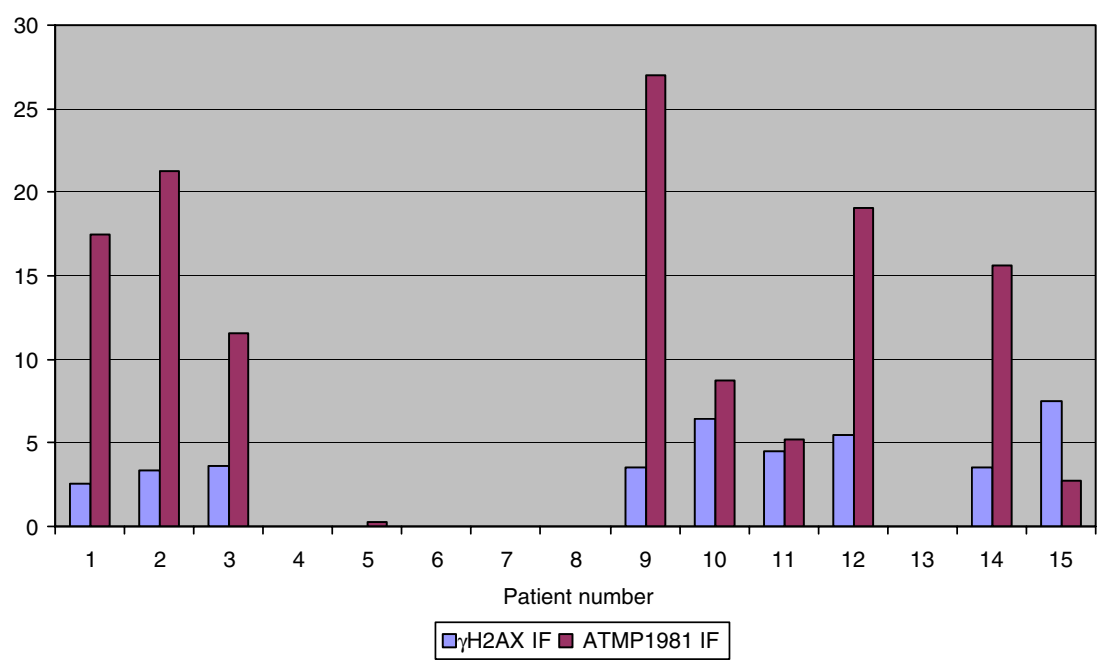




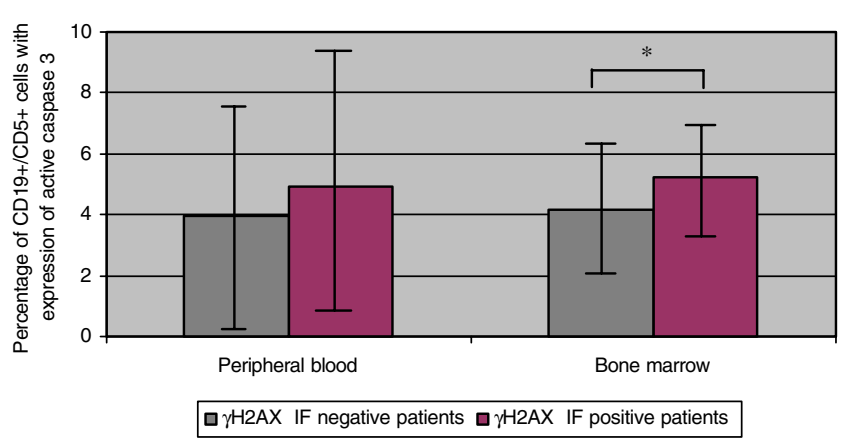

Fig. 5 The rates of apoptosis caused by simvastatin $(10 \mu \mathrm{M})$ in $24-\mathrm{h}$ ex vivo culture in the group of CLL patients $(n=9)$ in which the increase in $\gamma \mathrm{H} 2 \mathrm{AX}$ expression was above its "constitutive" level as a result of response to DNA damage (" $\gamma \mathrm{H} 2 \mathrm{AX}$ IF positive patients") and the group $(n=6)$ in which there was no increase in $\gamma \mathrm{H} 2 \mathrm{AX}$ expression above its "constitutive" level (" $\gamma \mathrm{H} 2 \mathrm{AX}$ IF negative patients"). The statistically significant difference is shown in the figure: ${ }^{*} p=0.02$

al. [16] and indicate that simvastatin induced apoptosis of leukemic CD19+/CD5+ cells at a higher rate than spontaneous apoptosis observed in control culture. This was the case in both in peripheral blood and bone marrow cell cultures. The induction of apoptosis was associated with a decrease in the BCL-2/BAX ratio, which was previously reported to accompany the simvastatin-induced apoptosis [27]. Moreover, we have shown that the pro-apoptotic effect of simvastatin is tumor-specific because such an effect was not observed in a non-leukemic lymphocyte population. Furthermore, this study is the first to demonstrate that simvastatin increased the frequency of apoptosis in combination with purine analogs. For most analyzed samples, the combined effect of simvastatin and purine analogs was seen as synergic when assessed based on the cooperative index.

Purine analogs are widely used for the treatment of CLL, and it has been reported that higher remission rates can be obtained when they are employed as a first therapy $[28,29]$. The widely used purine analogs-fludarabine and cladribine-have multidirected activities such as interference with DNA and RNA synthesis, DNA repair mechanisms, induction of apoptosis, and control of the cell cycle and signal transduction pathways in leukemic cells $[30,31]$. However, the use of purine analogs is connected with toxicities such as immunosuppression marked by a decrease in the CD4+/CD8+ ratio, leading to development of opportunistic infections, and myelosuppression, as well as to gastrointestinal toxicities including nausea, vomiting, and hepatic lesions [32]. Thus, the reduction in purine analogassociated toxicity by lowering their dose may be of great importance. The use of purine analogs in combination with simvastatin allows a reduction of their dose because of the synergic effect of the combination of these drugs. The benefit of in vitro combination of simvastatin and radiotherapy (in particular (213)Bi-alpha-irradiation ) in CLL was reported previously by Vandenbulcke et al. [33].

The role of prognostic factors in CLL seems to be very important, especially to distinguish the group of patients who require intensive treatment from those who will benefit from milder forms of therapy. There are several prognostic markers identified for CLL patients, such as laboratory parameters reflecting the tumor burden or disease activity (lymphocyte count, LDH elevation, bone marrow infiltration pattern and lymphocyte doubling time, $\beta 2$-microglobulin) or markers related to the biology of the disease (genomic aberrations or gene abnormalities and the mutation status of the variable segment of immunoglobulin heavy chain genes $(\mathrm{IgVH})$ ) or surrogate markers for these factors such as ZAP-70 and CD38 $[3,34]$. The presence or absence of somatic mutations in the $\mathrm{IgVH}$ and its surrogate markers has been described as the most powerful prognostic factors for CLL [4, 35, 36].

In this study, we assessed whether the rate of apoptosis caused by simvastatin differs between patients with better and worse prognosis. However, we detected that the rate of simvastatin-induced apoptosis of CLL cells was independent of ZAP-70 expression, CD38 expression, and clinical stadium according to Rai classification. Moreover, the percentage of apoptotic cells did not significantly correlate with such prognostic parameters as lymphocytosis, LDH, and $\beta 2$-microglobulin level. Thus, one can suppose that simvastatin can be equally effective in both the high-risk and the better-prognosis patients.

In the next part of the study, we examined the expression of phosphorylated H2AX and activated ATM in CD19+/CD5+ cells. The phosphorylated histone $\mathrm{H} 2 \mathrm{AX}$ (named $\gamma \mathrm{H} 2 \mathrm{AX}$ ) is the marker of DNA double-strand breaks, whereas ATM kinase is considered to be a major physiological mediator of H2AX phosphorylation. ATM activation is achieved by its autophosphorylation at Ser1981 [37, 38]. In our study, we observed an increase in $\gamma \mathrm{H} 2 \mathrm{AX}$ expression together with an increase in activated ATM in the same samples. Interestingly, such an increase was observed in most but not all cases. The analysis of $\gamma \mathrm{H} 2 \mathrm{AX}$ and phosphorylated ATM expression in the group of worse versus better prognosis revealed no significant connection with ZAP-70 and CD38 expression or with disease stage according to Rai classification. Furthermore, the genetic abnormalities were analyzed in the group of patients who did not respond to simvastatin by inducing DNA damage. Interestingly, in most cases the del 11q and the del $17 \mathrm{p}$ corresponded to abnormalities in ATM and p53, respectively. These data may prove that abnormalities in genes encoding proteins involved in the DNA damage response are the basis for the lack of $\mathrm{H} 2 \mathrm{AX}$ phosphorylation; however, further analysis in the larger group of patients is required. We also observed that in the group of patients in which H2AX was phosphorylated there was a significantly higher rate of apoptosis caused by simvastatin than in the 
group without detection of H2AX phosphorylation. Thus, phosphorylation of $\mathrm{H} 2 \mathrm{AX}$ makes the cells more prone to apoptosis and might be used as a predictor of apoptosis sensitivity.

This report is the first to reveal that simvastatin induces DNA damage as reflected by H2AX phosphorylation. However, simvastatin was reported to mediate oxidative DNA damage through generation of reactive oxidative species (ROS), which is known to trigger phosphorylation of H2AX. Otsuki et al. [23] showed that ROS participate in simvastatin-induced apoptosis of multiple myeloma cell lines, and anti-oxides prevented growth inhibition in several of them. Yang et al. [39] reported that simvastatin diminished K562 cell proliferation and induced apoptosis while simultaneously increasing the level of ROS and intracellular calcium concentration. Furthermore, the nitric oxide (NO) content and inducible NO synthase (iNOS) mRNA expression were significantly higher in the simvastatin-treated group than in the corresponding control group. Thus, their findings indicate that increased ROS, $\mathrm{NO}$, intracellular calcium concentration, and upregulated iNOS mRNA expression may be responsible for simvastatin-induced K562 cell apoptosis [39].

In conclusion, the results obtained in this study indicate that simvastatin can serve as an effective treatment for CLL patients as a single agent as well as in combination with purine analogs. This widely prescribed drug with a lack of severe side effects may be a good therapeutic option for CLL patients, especially older individuals for whom there are some limitations in using aggressive treatment. The synergism with purine analogs makes simvastatin an interesting drug for combined therapy in CLL patients. One of the mechanisms of simvastatin action appears to be connected with inducing DNA damage that, as a result, makes the leukemic cells undergo apoptosis.

Acknowledgments This work was supported by a research grant from the Polish Ministry of Science and Higher Education [N N402 208535].

Open Access This article is distributed under the terms of the Creative Commons Attribution Noncommercial License which permits any noncommercial use, distribution, and reproduction in any medium, provided the original author(s) and source are credited.

\section{References}

1. Calligaris-Cappio F, Hamblin TJ (1999) B-cell chronic lymphocytic leukemia: a bird of a different feather. J Clin Oncol 17:399-408

2. Hamblin TJ, Oscier DG (1997) Chronic lymphocytic leukemia: the nature of the leukemic cells. Blood Rev 11:119-128

3. Stilgenbauer S (2006) Chromic lymphocytic leukemia: genetics for predicting outcome. Hematology 2:185-190

4. Hamblin TJ, Davis Z, Gardiner A, Oscier DG, Stevenson FK (1999) Unmutated Ig $\mathrm{V}(\mathrm{H})$ genes are associated with a more aggressive form of chronic lymphocytic leukemia. Blood 94:1848-1854

5. Bonetti PO, Lerman LO, Napoli C, Lerman A (2003) Statin effects beyond lipid lowering - are they clinically relevant? Eur Heart J 24:225-248

6. McKenney JM (2002) New cholesterol guidelines, new treatment challenges. Pharmacotherapy 22:853-863

7. Bellosta S, Paoletti R, Corsini A (2004) Safety of statins: focus on clinical pharmacokinetics and drug interactions. Circulation 109:50-57

8. Bolego C, Baetta R, Bellosta S, Corsini A, Paoletti R (2002) Safety considerations for statins. Curr Opin Lipidol 13:637-644

9. Chan KK, Oza AM, Siu LL (2003) The statins as anticancer agents. Clin Cancer Res 9:10-19

10. Kaye JA, Jick H (2004) Statin use and cancer risk in the General Practice Research Database. Br J Cancer 90:635-637

11. Kaye JA, Meier CR, Walker AM, Jick H (2002) Statin use, hyperlipidaemia, and the risk of breast cancer. $\mathrm{Br} \mathrm{J}$ Cancer 86:1436-1439

12. Jakóbisiak M, Bruno S, Skierski J, Darzynkiewicz Z (1991) The cell cycle specific effects of lovastatin. Proc Natl Acad Sci USA 88:3628-3632

13. Bellosta S, Ferri N, Bernini F, Paoletti R, Corsini A (2000) Nonlipid-related effects of statins. Ann Med 32:164-176

14. Wong WW, Dimitroulakos J, Minden MD, Penn LZ (2002) HMGCoA reductase inhibitors and the malignant cell: the statin family of drugs as triggers of tumor-specific apoptosis. Leukemia 16:508-519

15. Lishner M, Bar-Sef A, Elis A, Fabian I (2001) Effect of simvastatin alone and in combination with cytosine arabinoside on the proliferation of myeloid leukemia cell lines. J Investig Med 49:319-324

16. Chapman-Shimshoni D, Yuklea M, Radnay J, Shapiro H, Lishner M (2003) Simvastatin induces apoptosis of B-CLL cells by activation of mitochondrial caspase 9. Exp Hematol 31:779-783

17. Sadeghi MM, Collinge M, Pardi R, Bender JR (2000) Simvastatin modulates cytokine-mediated endothelial cell adhesion molecule induction: involvement of an inhibitory $G$ protein. J Immunol $165: 2712-2718$

18. Chou TC (2010) Drug combination studies and their synergy quantification using the Chou-Talalay method. Cancer Res $70: 440-446$

19. ten Cate B, Samplonius DF, Bijma T, de Leij LF, Helfrich W, Bremer E (2007) The histone deacetylase inhibitor valproic acid potently augments gemtuzumab ozogamicin-induced apoptosis in acute myeloid leukemic cells. Leukemia 21:248-252

20. Bouzar AB, Boxus M, Defoiche J, Berchem G, Macallan D, Pettengell R et al (2009) Valproate synergizes with purine nucleoside analogues to induce apoptosis of B-chronic lymphocytic leukaemia cells. Br J Haematol 144:41-52

21. Newman A, Clutterbuck RD, Powles RL, Catovsky D, Millar JL (1997) A comparison of the effect of the 3-hydroxy-3-methylglutaryl coenzyme A (HMG-CoA) reductase inhibitors simvastatin, lovastatin and pravastatin on leukaemic and normal bone marrow progenitors. Leuk Lymphoma 24:533-537

22. Dimitroulakos J, Nohynek D, Backway KL, Hedley DW, Yeger H, Freedman MH, Minden MD, Penn LZ (1999) Increased sensitivity of acute myeloid leukemias to lovastatin-induced apoptosis: a potential therapeutic approach. Blood 93:1308-1318

23. Otsuki T, Sakaguchi H, Hatayama T, Fujii T, Tsujioka T, Sugihara T, Takata A, Hyodoh F, Eto M (2004) Effects of an HMG-CoA reductase inhibitor, simvastatin, on human myeloma cells. Oncol Rep 11:1053-1058

24. van der Spek E, Bloem AC, van de Donk NW, Bogers LH, van der Griend $\mathrm{R}$, Kramer $\mathrm{MH}$, de Weerdt O, Wittebol S, Lokhorst HM (2006) Dose-finding study of high-dose simvas- 
tatin combined with standard chemotherapy in patients with relapsed or refractory myeloma or lymphoma. Haematologica 91:542-545

25. Cafforio P, Dammacco F, Gernone A, Silvestris F (2005) Statins activate the mitochondrial pathway of apoptosis in human lymphoblasts and myeloma cells. Carcinogenesis 26:883-891

26. Bessler H, Salman H, Bergman M, Djaldetti M (2007) On the factors modulating the effect of statins on malignant cell proliferation. Cancer Investig 25:279-284

27. Blanco-Colio LM, Villa A, Ortego M, Hernández-Presa MA, Pascual A, Plaza JJ, Egido J (2002) 3-Hydroxy-3-methyl-glutaryl coenzyme A reductase inhibitors, atorvastatin and simvastatin, induce apoptosis of vascular smooth muscle cells by downregulation of Bcl-2 expression and Rho A prenylation. Atherosclerosis 161:17-26

28. Nabhan C, Gartenhaus RB, Tallman MS (2004) Purine nucleoside analogues and combination therapies in B-cell chronic lymphocytic leukemia: dawn of a new era. Leuk Res 28:429-442

29. Van den Neste E, Cardoen S, Offner F, Bontemps F (2005) Old and new insights into the mechanisms of action of two nucleoside analogs active in lymphoid malignancies: fludarabine and cladribine. Int J Oncol 27:1113-1124

30. Robak T (2005) Therapy of chronic lymphocytic leukemia with purine analogs and monoclonal antibodies. Transfus Apher Sci 32:33-44

31. Kobylinska A, Bednarek J, Blonski JZ, Hanausek M, Walaszek Z, Robak T (2006) In vitro sensitivity of B-cell chronic lymphocytic leukemia to cladribine and its combinations with mafosfamide and/or mitoxantrone. Oncol Rep 16:1389-1395

32. Morrison VA (2009) Infectious complications in patients with chronic lymphocytic leukemia: pathogenesis, spectrum of infec- tion, and approaches to prophylaxis. Clin Lymphoma Myeloma 9:365-370

33. Vandenbulcke K, Thierens H, De Vos F, Philippé J, Offner F, Janssens A, Apostolidis C, Morgenstern A, Bacher K, de Gelder V, Dierckx RA, Slegers G (2006) In vitro screening for synergism of high-linear energy transfer 213Bi-radiotherapy with other therapeutic agents for the treatment of B-cell chronic lymphocytic leukemia. Cancer Biother Radiopharm 21:364-372

34. Gribben JG (2008) Molecular profiling in CLL. Hematology Am Soc Hematol Educ Program 8:444-449

35. Crespo M, Bosch F, Villamor N, Bellosillo B, Colomer D, Rozman M, Marcé S, López-Guillermo A, Campo E, Montserrat E (2003) ZAP-70 expression as a surrogate for immunoglobulinvariable-region mutations in chronic lymphocytic leukemia. $\mathrm{N}$ Engl J Med 348:1764-1775

36. Oscier DG, Thompsett A, Zhu D (1997) Stevenson FK (1997) Differential rates of somatic hypermutation in $\mathrm{V}(\mathrm{H})$ genes among subsets of chronic lymphocytic leukemia defined by chromosomal abnormalities. Blood 89:4153-4160

37. Tanaka T, Halicka HD, Huang X, Traganos F, Darzynkiewicz Z (2006) Constitutive histone H2AX phosphorylation and ATM activation, the reporters of DNA damage by endogenous oxidants. Cell Cycle 17:1940-1945

38. Darzynkiewicz Z, Huang X, Okafuji M (2006) Detection of DNA strand breaks by flow and laser scanning cytometry in studies of apoptosis and cell proliferation (DNA replication). Meth Mol Biol 314:81-93

39. Yang YC, Xiao DW, Liu H, Chuan LM, Zeng YL, Zhou DA, Liu W, Xu GQ, Huang WF (2009) Mechanism of simvastatin-induced K562 cell apoptosis. Pharmacology 84:191-195 